\title{
Pneumococcal disease: Epidemiology and new vaccines
}

\author{
Catia Cillóniz, Antoni Torres
}

Department of Pneumology, Clinical Thoracic Institut, Hospital Clinic of Barcelona, August Pi i Sunyer Biomedical Research Institute (IDIBAPS), University of Barcelona, SGR 911, Ciber de Enfermedades Respiratorias, Barcelona, Spain

\begin{abstract}
Streptococcus pneumoniae causes invasive and noninvasive infections. Among infectious diseases, invasive pneumococcal disease (IPD) is a leading cause of morbidity and mortality in children and adults. Community acquired pneumonia in adults is the main presentation of non-IPD and is the most common infectious source of IPD. The incidence, severity and mortality of pneumococcal disease vary widely depending on several factors, some are host related, and others are organism related. After introduction of the vaccine, rates of pneumococcal disease caused by vaccine serotypes have dramatically decreased among vaccinated children, nonvaccinated children, and adults. However, incidents of pneumococcal disease due to new emerging nonvaccine serotypes and antimicrobial resistance have increased. Continuous monitoring and surveillance studies focused on the clinical and molecular epidemiology of pneumococcal disease will be required to understand the impact of the new vaccines and possible alteration in the pattern of disease presentation.
\end{abstract}

Key words: Pneumococcal disease, pneumococcus, Streptococcus pneumoniae

\section{INTRODUCTION}

Pneumococcal disease is a major public health problem worldwide. The clinical spectrum of pneumococcal infections ranges from acute otitis media to pneumonia and invasive pneumococcal disease (IPD) such as meningitis and septicemia. Currently, 93 serotypes and 46 serogroups have been documented, and the last serotypes reported are serotype 6C, 6D and 11E. $\cdot^{[1-3]}$ Approximately, 10 serogroups are responsible for most of the pneumococcal infections. The disease most frequently affects individuals at extremes of age and those with immunological impairment (children

\section{Address for correspondence:}

Prof. Antoni Torres, Department of Pneumology, Hospital Clinic of Barcelona, Barcelona, Spain.

E-mail: catiacilloniz@clinic.ub.es

\begin{tabular}{|l|l|}
\hline Access this article online & \\
\hline Quick Response Code: & \\
\hline & Website: \\
& www.caijournal.com \\
& \\
\hline
\end{tabular}

or adults).$^{[4]}$ Nevertheless, a significant proportion of adults who develop pneumococcal infection particularly IPD have no apparent preexisting risk factor. ${ }^{[5]}$ Most cases of pneumococcal disease are caused by a limited number of serotypes that vary in nasopharyngeal carriage, infectivity and virulence. Recent epidemiological study estimates about 1.6 million people, including up to 1 million children aged $<5$ years, die of IPD every year mainly in developing countries. ${ }^{[6,7]}$ Case fatality rates ranged from $10 \%$ to $30 \%$ in adults with IPD but are much lower $(<3 \%)$ in children. ${ }^{[6]}$

Pneumococcal vaccines effectively prevent the more severe pneumococcal disease caused by vaccine serotypes and also reduce the risk of nasopharyngeal colonization by the serotypes. Widespread use of heptavalent pneumococcal conjugate vaccine 7 (PCV7) for the pediatric population has significantly decreased the incidence of IPD in both children and nonvaccinated adults (by herd immunity). ${ }^{[8-10]}$ Unfortunately, non-PCV7 serotypes have relatively increased among asymptomatic carriers, and the incidence of IPD due to these serotypes are increasing globally. ${ }^{[11,12]}$ In 2011 , a new 13-valent PCV was suggested for the prevention of IPD in persons 50 years and older in Europe, and in 2013, the suggestion was expanded to cover all ages. Recent studies on the impact of PCV13 vaccine report a lower incidence of pneumococcal disease by vaccine serotypes and the relative 
increase of pneumococcal disease by nonvaccine serotypes especially $23 \mathrm{~B}$ and $15 \mathrm{~A} \cdot{ }^{[13-15]}$ This suggests that the serotype replacement is occurring again. With the availability of an effective conjugate vaccine, pneumococcal disease is also the leading cause of death among vaccine-preventable infectious diseases. ${ }^{[6]}$

\section{PNEUMOCOCCAL COLONIZATION}

Pneumococcal disease may take place when two situations coincide:

1. The host is colonized with a pneumococcal strain against which immunity has not yet been established,

2. An alteration of the natural barriers or host immune system has occurred. ${ }^{[16]}$

The nasopharynx of humans is the ecological niche for many bacterial species including pneumococcus. At least once in our lives, it gets colonized by pneumococcus. In general, it acts simply as an asymptomatic carriage, but in some cases the spread of pneumococcus from the nasopharynx to the lower respiratory tract or other sites may cause pneumococcal disease. ${ }^{[4]}$

The nasopharyngeal carriage rate peaks in children with the highest rates found in developing countries with reports of $80-90 \%$ of children colonized mostly during the $1^{\text {st }}$ year of life in some countries in Africa. ${ }^{[17]}$

Nasopharyngeal carriage rates in healthy children range from $20 \%$ to $50 \%$ and in healthy adult population they range from $5 \%$ to $30 \% \cdot{ }^{[4,18]}$

Risk factors for nasopharyngeal carriage in children include: Winter season, age $<6$ years, having young siblings and attendance in day care centers. In adults, the risk factors include: Current smoker, asthma, and upper respiratory infection. In children, colonization may persist for a mean of 4 months but is much shorter in adults (usually 2-4 weeks). ${ }^{[19]}$ The duration of colonization can range from days to months depending on serotypes. ${ }^{[20]}$ Transmission of pneumococci from children to other children or adults through household contacts is the major cause of nasopharyngeal carriage and pneumococcal disease [Figure 1].

Not all pneumococcal serotypes are equally able to cause disease; the capsular polysaccharide is the major virulence factor, and those serotypes that produce large amounts of polysaccharide are likely to be more virulent than others. After invasion, the capsular polysaccharide also protects the pathogen by inhibiting neutrophil phagocytosis and classic complement mediated bacterial killing. Some of the important factors in the development of pneumococcal disease include the invasive properties of serotype, the ability of an organism to evade the immune system, and the absence of a type-specific pneumococcal antibody. ${ }^{[21]}$

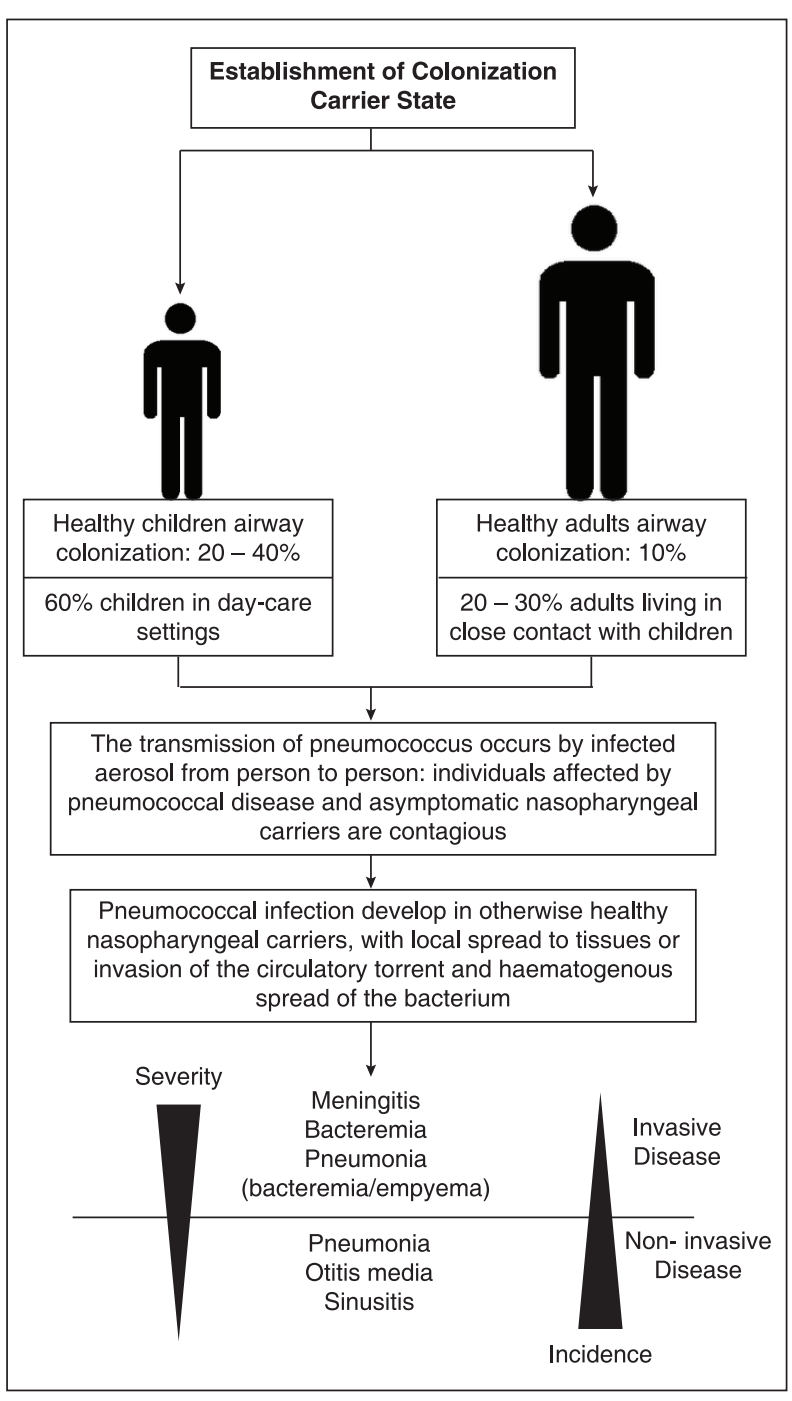

Figure 1: Pneumococcal disease

\section{INVASIVE PNEUMOCOCCAL DISEASE AND THE PRINCIPAL RISK FACTORS}

Invasive diseases caused by pneumococcus include meningitis, bacteremia, and pneumonia with bacteremia and/or empyema. The incidence of IPD in any population depends on the geographical location, season, prevalent serotype, age, and vaccination status of the population.

Extremes of age ( $<2$ years or $\geq 65$ years), ethnicity (African-Americans, American Indians, Native Alaskans, and Australian Aborigines), existence of comorbidities (pulmonary, neurological, hepatic, diabetes mellitus, and renal conditions), alcoholism, immunosuppression (asplenia, human immunodeficiency virus [HIV], and sickle cell), and anatomic abnormalities (cerebrospinal fluid leak, cochlear implant or congenital heart disease) are well known risk factors associated with an increased susceptibility to IPD and are further associated with higher mortality. ${ }^{[19,21]}$ 
On the other hand, in healthy children the exposure to cigarette smoke and multiple children in the household are the risk factors for IPD. In the case of inmunocompetent adults the incidence of IPD is increased with the following comorbidities: Congestive heart failure, chronic lung disease, asthma, diabetes mellitus, neurological disorders, alcohol abuse, cigarette smoking, recent influenza infection, institutionalization, male gender. ${ }^{[22]}$

\section{EPIDEMIOLOGY}

Epidemiological data in United States in 2009 showed that the overall case rate of IPD was 14.3/100,000, with the highest case rates in two age groups: Children younger than 1 year and adults aged 65 years or older. In these groups, the case rates were 37.1/100,000 and 38.7/100,000, respectively. The group aged 65 years, or older has the highest rate of death from IPD (6.56/100,000 persons). ${ }^{[23]}$ Pneumococcal infection causes an estimated 40,000 deaths annually in the United States, accounting for more deaths than any other vaccinepreventable bacterial disease. ${ }^{[24]}$

In Europe, the incidence of IPD varies considerably both by country and age group. The highest rate of IPD in Europe and in the rest of the world is reported in children of 2 years of age, declining steadily in the years thereafter. In the age group of children for whom the PCV7 is currently licensed in Europe ( $<2$ years), the incidence ranges from 14 cases/100,000 children in Germany and The Netherlands to more than 90 cases/100,000 in Spain. These differences between European countries cannot be readily explained, but differences in surveillance systems and definitions of IPD may also contribute to this phenomenon. In European countries, reliable incidence data are not available. ${ }^{[25]}$

Pneumococcal diseases are responsible for significant morbidity and mortality in children in the Asia-Pacific region; incidences are highest in indigenous and younger children, with rates around 100-200 cases/100,000 children aged $<2$ years. However, a particularly high incidence of IPD of 1500 cases/100,000 children aged $<5$ years has been reported in India based on hospital admissions for IPDassociated diagnoses.

In a pilot study conducted among hospital and ambulatory patients in Chile, the incidences of IPD overall and bacteremia in particular were estimated to be 33.9 and 27.0 cases, respectively, per 100,000 children aged $<36$ months. In the same study, fatality among hospitalized children was found to be $9.9 \% .{ }^{[26]}$ An estimated 12,000-28,000 deaths due to pneumococcal disease occur in the Latin America and Caribbean children annually. ${ }^{[27]}$

The mortality rate from pneumococcal infections is significantly higher than in developed countries; it is estimated that mortality rate in some of the poorest regions in the world can be over 10 times higher than in developed countries. ${ }^{[26]}$

\section{NONINVASIVE PNEUMOCOCCAL DISEASE AND THE PRINCIPAL RISK FACTORS}

Non-IPD is frequent, but less severe and includes acute otitis media, sinusitis and community acquired pneumonia (CAP).

Pneumococcal pneumonia represents the main burden of pneumococcal disease, since it has a high case fatality rate ( $15 \%$ of hospitalized patients) and a high incidence.

Streptococcus pneumoniae is the leading cause of CAP in adults in Europe and in the United States accounting for about $30-35 \%$ of the cases. ${ }^{[28-31]}$

There are three factors for the progression of an infection such as pneumococcal pneumonia: Pathogen factor (virulence and presence of resistance genes), host factors (e.g., age, sex, comorbidities, and immune status) and environment (e.g., temperature, occupational exposure, and coexistence with animals). CAP incidence increase with age and the presence of comorbidity, and is higher in males than females. ${ }^{[32,33]}$

\section{Age and gender}

Pneumococcal pneumonia results in significant morbidity, leading to high rates of hospitalizations, especially in elderly patients. Hospitalization rates due to pneumococcal pneumonia in Spain were 0.25/1,000 in patients aged 50-54 years versus 4.21/1,000 in those $\geq 85$ years of age. ${ }^{[33]}$

The study by Torres et al. ${ }^{[33]}$ reported an increased risk of CAP in men (compared with women) and in patients $\geq 65$ years of age.

\section{Comorbidities}

Patients with certain comorbid conditions, such as previous history of pneumonia, chronic respiratory disease, chronic obstructive pulmonary disease (COPD), or HIV infection are at risk of pneumococcal CAP. ${ }^{[33]}$

Streptococcus pneumoniae is the most frequently isolated pathogen in the respiratory tract during pneumonia in patients presenting COPD. ${ }^{[34]}$

The study of Müllerova et al. reported the highest overall incidence of COPD: 22.4/1000 person/year, with rates of 23.1 and 21.4 in men and women, respectively. ${ }^{[35]}$

Chronic cardiovascular disease increased the risk of CAP up to three-fold from 1.4 to 3.2/1000 person/year. Additional studies supported an association between chronic heart disease and the risk of CAP. 
Cerebrovascular disease/stroke and dementia approximately doubled the risk of CAP.

Other neurological or psychiatric conditions were also associated with an increased risk of CAP in some studies. CAP in patients with depression or bipolar disorder ranged from 1.75 to $2.54 / 1000$ person/year.

Patients admitted to hospital with diabetes mellitus remain at increased risk for pneumococcal infection, data from several studies suggested that the diabetes was associated with a moderate increase in the risk of CAP. Chronic liver or renal disease increased the risk of CAP approximately two-fold.

High incidence rates of pneumococcal pneumonia were also reported in immunocompromised patients. Bacterial pneumonia is the most frequent infection in HIV patients, thus recurrent bacterial pneumonia (two episodes of CAP within 1 year period) was included as a defining condition for acquired immunodeficiency syndrome. ${ }^{[36,37]}$ HIV infection is associated with 10-fold increase incidence of bacterial pneumonia. ${ }^{[38]} \mathrm{A}$ recent study of CAP in HIV patients show pneumococcus was the most frequent pathogens in HIV patients with CD4+ T-cell counts $\geq 200 / \mathrm{mm}$. ${ }^{[39]}$

Another important risk factor for pneumococcal pneumonia is a previous respiratory viral infection. A study by Yoon et al. suggested that previous respiratory viral infection might be one of the risk factors affecting the clinical severity of pneumococcal pneumonia. ${ }^{[40]}$ In patients with immunodeficiency or chronic lung diseases, infrequently colonizing invasive serotypes would be more likely to cause pneumococcal pneumonia after preceding respiratory viral illness. ${ }^{[41]}$

\section{LIFESTYLE FACTORS}

Patients with specific lifestyle factors including being underweight, smoking, alcohol consumption, and regular contact with children in day care, are at risk for pneumococcal CAP. ${ }^{[33]}$

There was consistent evidence that smoking was associated with an increased risk of CAP. Changes in the composition of the oropharyngeal microflora are associated with continuous exposure to cigarette smoke. ${ }^{[42]}$ Pathogens such as $S$. pneumoniae are frequent found in smokers and are colonizer in COPD patients. ${ }^{[43]}$ Parental smoking increases infant carriage of $S$. pneumoniae in general and the serotypes are included in the PCV7 vaccine in particular. ${ }^{[4]}$

In a study of bacterial pneumonia in HIV patients, current smokers had more than $80 \%$ higher risk of pneumonia compared with those who never smoked. ${ }^{[45,46]}$
A study published by Bello et al. ${ }^{[47]}$ showed that current smokers with pneumococcal CAP often develop severe sepsis and require hospitalization at a younger age despite fewer comorbid conditions. Almirall et al., ${ }^{[48]}$ in a recent study, found that passive smoking at home is a risk factor for CAP in older adults ( $\geq 65$ years).

Chronic alcohol abuse impairs airway defenses against microbial invasion and infections and amplifies the risk for serious pneumonias as well as their complication including sepsis and acute lung injury. ${ }^{[4,50]}$

Samokhvalov et al., ${ }^{[51]}$ in a meta-analysis, showed that subjects who consumed 24, 60, and $120 \mathrm{~g}$ of pure alcohol daily had 1.12 (95\% confidence intervals [CI]: 1.02-1.23), 1.33 (95\% CI: 1.06-1.67), and 1.76 (95\% CI: 1.13-2.77) risks for CAP relative to nondrinkers, respectively. Other studies showed that bacterial pneumonias particularly caused by encapsulated microorganism, are related to alcohol consumption. ${ }^{[51-53]}$

Being underweight was generally associated with an increased risk of CAP. Obesity is a complex condition that is characterized by excess white adipose tissue and is often accompanied by other comorbid conditions (e.g., diabetes and gastroesophageal reflux) and is known to compromise host defense against infection. The accumulation of adipose tissue may attenuate pulmonary host defense through metabolic disturbances that often accompany obesity. This leads to dysregulated immune response, impaired chemotaxis, and altered macrophage differentiation. ${ }^{[54,55]}$

\section{CAUSES OF PNEUMOCOCCAL DISEASES BY SEROTYPE}

Pneumococcal serotypes are known to differ in their invasiveness. Traditionally, the serotypes chosen for the vaccine have been based on the rank order incidence of disease. These serotypes are often the most prevalent in carriage, but they do not necessarily exhibit the highest potential for invasiveness. ${ }^{[56]}$

About 20 serotypes of $S$. pneumoniae are responsible for more than $80 \%$ of IPD, and the 13 most common serotypes cause at least $70-75 \%$ of IPD in children worldwide. ${ }^{[6]}$ The dominant serotypes associated with IPD worldwide include $14,4,1,6 \mathrm{~A}, 6 \mathrm{~B}, 3,8,7 \mathrm{~F}, 23 \mathrm{~F}, 18 \mathrm{C}, 19 \mathrm{~F}$, and $9 \mathrm{~V}$. In young children, seven serotypes $(1,5,6 \mathrm{~A}, 6 \mathrm{~B}, 14,19 \mathrm{~F}$, and $23 \mathrm{~F}$ ) accounted for more than half of IPD in every region. Serotypes causing IPD vary greatly across geographic regions (e.g., serotypes 1 and 5 are an important cause of IPD in Africa, Asia, but are uncommon in Europe and United States ${ }^{[22]}$ ), and several factors may contribute to these variations. 
The introduction of PCV7 in 2000 had a profound impact on the sero-epidemiology of pneumococcal disease, with significant declines of vaccine serotypes observed in pediatric and adult patients. Initial reports indicated that the decline in vaccine serotypes was also associated with a decline in the frequency of drug resistance, due to the fact that the serotypes targeted by PCV7 were among the more common drug resistant types in the prevaccine era. However, the emergence of nonvaccine serotypes in recent years has been driven, in part, by antimicrobial drug selection pressures, and is changing the epidemiology of pneumococcal drug resistance. ${ }^{[57]}$

The distribution of serotypes changes over time. Serotype 3 has declined in frequency over the past few decades whereas serotype 14 has become more prevalent. ${ }^{[22]}$ A large retrospective study in 1075 hospitalized adult patients with IPD from The Netherlands found that serogroups known to have high invasive disease potential in children (serogroups 1, 5, and 7) affected relatively healthy adults whereas those previously shown to have low or intermediate invasive disease potential (serogroups $3,6,8,15,19,23,33$, and 38) were more likely to affect more fragile individuals at an older age and/or those with underlying conditions. ${ }^{[58]}$

\section{PNEUMOCOCCAL VACCINES}

Development of an effective vaccine was extremely challenging mainly due to the low immunogenicity of polysaccharides, which are the target of opsonizing antibodies. Two vaccine formulations (pneumococcal polysaccharide vaccine and pneumococcal polysaccharide protein conjugate vaccine) are available to prevent pneumococcal infection [Figure 2].

The development of pneumococcal polysaccharide vaccines for adults and the efficacy of pneumococcal polysaccharide protein conjugate vaccines in infants and children have confirmed that active immunity to the polysaccharide can provide excellent protection against the invasive disease by pneumococci of the same serotype, and in some cases

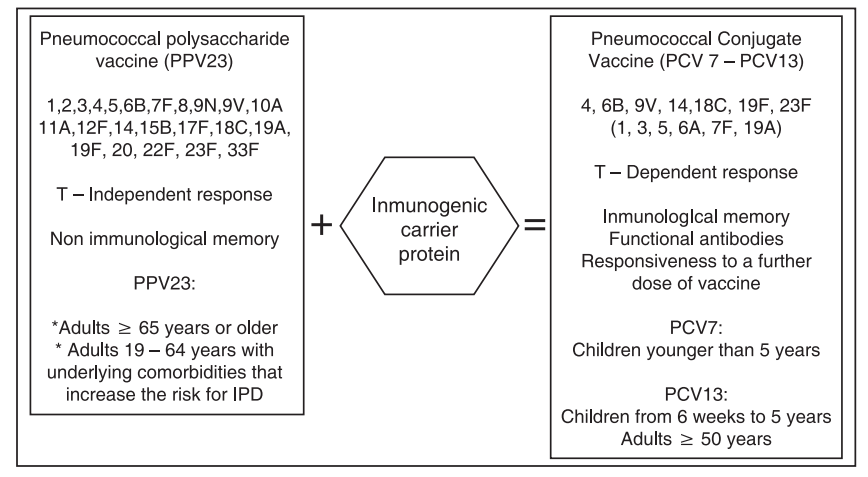

Figure 2: Pneumococcal vaccines protection against cross-reacting serotypes within the same serogroup. Vaccination of high-risk groups in addition to individual protection reduces nasopharyngeal colonization by vaccine-related serotypes.

\section{POLYSACCHARIDE VACCINE: 23-VALENT PNEUMOCOCCAL POLYSACCHARIDE VACCINE}

Licensed in 1983, this vaccine contain purified capsular polysaccharides from 23 pneumococcal serotypes $(1,2,3$, $4,5,6 \mathrm{~b}, 7 \mathrm{~F}, 8,9 \mathrm{~N}, 9 \mathrm{~V}, 10 \mathrm{~A}, 11 \mathrm{~A}, 12 \mathrm{~F}, 14,15 \mathrm{~B}, 17 \mathrm{~F}, 18 \mathrm{C}$, 19F, 19A, 20, 22F, 23F, and 33F). Polysaccharides primarily induce a B-cell dependent immune response via release of immunoglobulin M (IgM). The vaccine covers $85-90 \%$ of serotypes responsible for invasive disease. The $0.5 \mathrm{ml}$ dose of the vaccine contains $25 \mathrm{mg}$ of polysaccharide for each of the 23 included serotypes in isotonic saline solution with $0.25 \%$ phenol as a preservative.

This vaccine was licensed for adults aged 65 years or older, as well as adults aged 19-64 years with underlying medical conditions that increase the risk for pneumococcal disease. This vaccine is not recommended for children $<2$ years of age, due to their immature immune system. Vaccination of adults with polysaccharide vaccines requires re-vaccination after 5 years. ${ }^{[59]}$ Nonresponders to PPV23 are frequent in older patients. ${ }^{[60]}$

\section{Limitation of pneumococcal polysaccharide}

vaccine 23

Most of the studies suggest that the PPV23 confer low protection against IPD, and data concerning the prevention of pneumococcal pneumonia and mortality in the adult population is less clear. ${ }^{[61]}$

- Some of the serotypes included in the PPV23 are less immunogenic. The capsular polysaccharide of serotypes $6(6 \mathrm{~A}$ y $6 \mathrm{~B}), 14,19 \mathrm{~F}$, and $23 \mathrm{~F}$ are unable to produce antibodies in children aged under 2 years and have poor immunogenicity even in adults. Moreover, these are the most frequently isolated serotypes in children with systemic infections.

- Prior analyses suggest that adult PCV could prevent more disease than PPV23 due to its potential effectiveness against both nonbacteremic pneumococcal pneumonia and IPD.

- Primary PPV23 vaccination resulted in an immune state, in which a subsequent PPV23 dose generally yielded inferior responses compared with the initial response with poor or absent immunogenicity.

- The levels of antibodies specific for the different serotypes substantially declined 5-10 years after vaccination.

- The immune response produced by the vaccine antigens is independent of T-cells, therefore, do not induce immunological memory. The vaccine mostly induced IgM production. 
Polysaccharide conjugate vaccine: Pneumococcal conjugate vaccine $7 /$ pneumococcal conjugate vaccine 13

The heptavalent conjugate vaccine (PCV7) was approved in the USA in 2000 and in Europe and much of the rest of the world in 2001 or later. PCV7 contains: Serotypes 4, 6B, 9V, $14,18 \mathrm{C}, 19 \mathrm{~F}$, and $23 \mathrm{~F}$, and are individually conjugated to a protein carrier; nontoxic diphtheria cross-reactive material $\mathrm{CRM}_{197}{ }^{[62]}$

Employment of this pneumococcal vaccine is particularly successful in the vaccination of young children. This vaccine provides an optimal level of protection against invasive disease, with percentages of efficacy approximately $90 \%$. The vaccine was license for all children younger than 2 years, and for children younger than 5 years with high-risk of IPD. The routine use of PCV7 has resulted not only in a tremendous reduction of invasive infection in children, but also in decreased rates of pneumococcal disease in adults. This result, likely caused by decreased nasopharyngeal carriage, demonstrates a direct or herd effect in the transmission of bacteria from children to adults.

Despite the success of PCV7, studies have also noted an increase in the incidence of IPD caused by nonvaccine serotypes, which remain as a major cause of the disease. Eradication of vaccine serotypes in asymptomatic carriers has created an ecological niche for nonvaccine serotypes ("replacement"). These strains, termed replacement strains, were 1, 3, 5, 6A, 6C, 7F, 12F, 19A, and 22F. In The Netherlands, IPD caused by nonvaccine serotypes has increased since the introduction of PCV7 and reduced the overall direct effects of PCV7 and offset the potential positive herd protection benefits in nonvaccinated individuals. ${ }^{[63]}$

Also, there is an evidence of increased incidence in multidrug-resistant disease due to serotype 19A, as well as nasopharyngeal acquisition. ${ }^{[64,65]}$ However, other factors besides PCV7 introduction may also play a role in the increase incidence of serotype 19A since this serotype emerged in countries that have not yet introduced the vaccine. ${ }^{[66]}$

The Food and Drug Administration (FDA) on February 2010 approved the use of a new 13-valent pneumococcal polysaccharide-protein conjugate vaccine (PCV13), PCV13 contains capsular polysaccharides from the serotypes 1, 3, 4, $6 \mathrm{~A}, 7 \mathrm{~F}, 9 \mathrm{~V}, 14,18 \mathrm{C}, 19 \mathrm{~A}, 19 \mathrm{~F}$, and $23 \mathrm{~F}$ that are individually conjugated to $\mathrm{CRM}_{197}$ carrier. PCV13 contains $2.2 \mu \mathrm{g}$ of polysaccharide from each of 12 serotypes and approximately $4.4 \mu \mathrm{g}$ of polysaccharide from serotype $6 \mathrm{~B}$.

Polysaccharide conjugate vaccinel3 is formulated and manufactured using the same processes as PCV7 and was licensed by FDA on the basis of studies demonstrating safety and an ability comparable to that of PCV7 to elicit antibodies protective against IPD. PCV13 is approved for use among children aged 6 weeks to 5 years and replaces PCV7, and for adults aged 50 years and older. PCV13 contains the seven serotypes included in PCV7 (serotypes 4, $6 \mathrm{~B}, 9 \mathrm{~V}, 14,18 \mathrm{C}, 19 \mathrm{~F}$, and $23 \mathrm{~F}$ ) and six additional serotypes $(1,3,5,6 \mathrm{~A}, 7 \mathrm{~F}$, and 19A). PCV13 also is approved for the prevention of otitis media caused by the seven serotypes also covered by PCV7. However, no efficacy data for prevention of otitis media are available for the six additional serotypes. ${ }^{[67]}$

Recent studies show that the incidence of some nonvaccine serotypes occurring again. ${ }^{[13,15,68]}$ in Norway the nonvaccine serotypes $23 \mathrm{~B}$ and $15 \mathrm{~A}$ were reported ${ }^{[13]}$ after PCV13 introduction in 2011. Ben-Shimol et al. Reported that the rate of IPD caused by non-PCV13 serotypes in Israel increased by $54 \%$ in comparison to the PCV7 and the prePCV periods in children $<5$ years old. The increase in IPD caused by non-PCV13 IPD was similar in magnitude among children $<2$ and 2-4 years old. Of all non-PCV13 disease, serotypes $12 \mathrm{~F}, 15 \mathrm{~B} / \mathrm{C}$, and $33 \mathrm{~F}$ were the most common, causing $28.3 \%, 8.0 \%$ and $6.2 \%$ of all non-PCV13 episodes in the entire study period, respectively, and $38.8 \%, 10.9 \%$ and $7.5 \%$ of all non-PCV13 episodes in the PCV13 period, respectively.

The more frequent reported nonvaccine PCV13 serotypes before the introduction of $\mathrm{PCV} 13$ vaccines were: $23 \mathrm{~A}, 23 \mathrm{~B}$, $12 \mathrm{~F}, 15 \mathrm{~A} / 15 \mathrm{~B} / 15 \mathrm{C}, 31,33 \mathrm{~F}, 7 \mathrm{C}$, and 8 .

As this suggests that the serotype replacement is again occurring, continued monitoring of IPD is important so that adaptations to vaccine recommendations can be issued promptly.

\section{New vaccine formulations}

Higher valency PCV that target up to 15 serotypes (PCV15, Merck) are being evaluated and have the potential to broaden protection, but with a trade-off of a higher cost and manufacturing complexity. ${ }^{[69]}$ This vaccine includes the serotypes 1, 3, 4, 5, 6A, 6B, 7F, 9V, 14, 18C, 19A, 19F, 22F, $23 \mathrm{~F}$, and $33 \mathrm{~F}$ that are conjugated to $\mathrm{CRM}_{197}$. The results of preclinical evaluation of PCV15 indicate that antibody responses to PCV15 and PCV7 were comparable for the 7 common serotypes and that postvaccination responses to PCV15 were $>10$-fold higher than baseline for the 8 additional serotypes.

Pneumococcal hybrid conjugate and protein vaccines may be another promising alternative long-term strategy to broaden serotype coverage in both industrialized and low-resource settings.

A protein pneumococcal vaccine that includes a pneumococcal histidine triad protein $\mathrm{D}$, a virulence factor and pneumococcal choline-binding protein A bacterial 
surface antigen, has the potential to offer expanded protection against a broad spectrum of pneumococcal serotypes in a single formulation, ${ }^{[70]}$ and may be more accessible for resource-poor populations.

\section{CONCLUSION}

Streptococcus pneumoniae remains one of the most important causes of morbidity and mortality in adults and children throughout the world. According to the World Health Organization, pneumococcus is responsible for approximately 1.6 million deaths every year, of which nearly 1 million deaths are in children aged $<5$ years, mostly in developing countries. ${ }^{[6]} \mathrm{A}$ limited number of serotypes are responsible for most cases of IPD globally.

Several studies have demonstrated the efficacy of pneumococcal vaccines in general. Pneumococcal vaccines decreased the resistant pneumococci in vaccinated and unvaccinated populations by reducing colonization of antibiotic-resistant serotypes, protecting the vaccinated population, and preventing the spread of the disease to others.

Serotype replacement and the development of antibioticresistant remains an important issue to consider in the future research. ${ }^{[71]}$

It is important to continue IPD surveillance in order to identify the emergence of new relevant strains to direct the formulation of future conjugate vaccines, depending on the level of serotype replacement.

\section{REFERENCES}

1. Park IH, Pritchard DG, Cartee R, Brandao A, Brandileone MC, Nahm MH. Discovery of a new capsular serotype $(6 \mathrm{C})$ within serogroup 6 of Streptococcus pneumoniae. J Clin Microbiol 2007; 45:1225-33.

2. Jin P, Kong F, Xiao M, Oftadeh S, Zhou F, Liu C, et al. First report of putative Streptococcus pneumoniae serotype 6D among nasopharyngeal isolates from Fijian children. J Infect Dis 2009;200:1375-80.

3. Calix JJ, Nahm MH. A new pneumococcal serotype, 11E, has a variably inactivated wcjE gene. J Infect Dis 2010;202:29-38.

4. Bogaert D, De Groot R, Hermans PW. Streptococcus pneumoniae colonisation: The key to pneumococcal disease. Lancet Infect Dis 2004;4:144-54.

5. Klemets P, Lyytikäinen O, Ruutu P, Ollgren J, Nuorti JP. Invasive pneumococcal infections among persons with and without underlying medical conditions: Implications for prevention strategies. BMC Infect Dis 2008;8:96.

6. Pneumococcal conjugate vaccine for childhood immunization-WHO position paper. Wkly Epidemiol Rec 2007;82:93-104.

7. O'Brien KL, Wolfson LJ, Watt JP, Henkle E, Deloria-Knoll M, McCall N, et al. Burden of disease caused by Streptococcus pneumoniae in children younger than 5 years: Global estimates. Lancet 2009;374:893-902.

8. Shah SS, Ratner AJ. Trends in invasive pneumococcal diseaseassociated hospitalizations. Clin Infect Dis 2006;42:e1-5.

9. Alanee SR, McGee L, Jackson D, Chiou CC, Feldman C, Morris AJ, et al. Association of serotypes of Streptococcus pneumoniae with disease severity and outcome in adults: An international study. Clin Infect Dis 2007;45:46-51.

10. Whitney CG, Farley MM, Hadler J, Harrison LH, Bennett NM, Lynfield $\mathrm{R}$, et al. Decline in invasive pneumococcal disease after the introduction of protein-polysaccharide conjugate vaccine. N Engl J Med 2003;348:1737-46.

11. Bender JM, Ampofo K, Korgenski K, Daly J, Pavia AT, Mason EO, et al. Pneumococcal necrotizing pneumonia in Utah: Does serotype matter? Clin Infect Dis 2008;46:1346-52.

12. Muñoz-Almagro C, Jordan I, Gene A, Latorre C, Garcia-Garcia JJ, Pallares R. Emergence of invasive pneumococcal disease caused by nonvaccine serotypes in the era of 7-valent conjugate vaccine. Clin Infect Dis 2008;46:174-82.

13. Steens A, Bergsaker MA, Aaberge IS, Rønning K, Vestrheim DF. Prompt effect of replacing the 7-valent pneumococcal conjugate vaccine with the 13-valent vaccine on the epidemiology of invasive pneumococcal disease in Norway. Vaccine 2013;31:6232-8.

14. Harboe ZB, Dalby T, Weinberger DM, Benfield T, Mølbak K, Slotved $\mathrm{HC}$, et al. Impact of 13-valent pneumococcal conjugate vaccination in invasive pneumococcal disease incidence and mortality. Clin Infect Dis 2014;59:1066-73.

15. Moore CE, Paul J, Foster D, Mahar SA, Griffiths D, Knox K, et al. Reduction of invasive pneumococcal disease 3 years after the introduction of the 13-valent conjugate vaccine in the Oxfordshire region of England. J Infect Dis 2014;210:1001-11.

16. Koedel U, Scheld WM, Pfister HW. Pathogenesis and pathophysiology of pneumococcal meningitis. Lancet Infect Dis 2002;2:721-36.

17. Hill PC, Akisanya A, Sankareh K, Cheung YB, Saaka M, Lahai G, et al. Nasopharyngeal carriage of Streptococcus pneumoniae in Gambian villagers. Clin Infect Dis 2006;43:673-9.

18. Ferreira DM, Jambo KC, Gordon SB. Experimental human pneumococcal carriage models for vaccine research. Trends Microbiol 2011;19:464-70.

19. Bridy-Pappas AE, Margolis MB, Center KJ, Isaacman DJ. Streptococcus pneumoniae: Description of the pathogen, disease epidemiology, treatment, and prevention. Pharmacotherapy 2005;25:1193-212.

20. Smith T, Lehmann D, Montgomery J, Gratten M, Riley ID, Alpers MP. Acquisition and invasiveness of different serotypes of Streptococcus pneumoniae in young children. Epidemiol Infect 1993;111:27-39.

21. Mook-Kanamori BB, Geldhoff M, van der Poll T, van de Beek D. Pathogenesis and pathophysiology of pneumococcal meningitis. Clin Microbiol Rev 2011;24:557-91.

22. Lynch JP $3^{\text {rd }}$, Zhanel GG. Streptococcus pneumoniae: Epidemiology, risk factors, and strategies for prevention. Semin Respir Crit Care Med 2009;30:189-209.

23. Centers for Disease Control and Prevention Web Site. Active Bacterial Core Surveillance Report, Emerging Infections Program Network, Streptococcus Pneumonia, 2009. 2014.

24. Obaro S, Adegbola R. The pneumococcus: Carriage, disease and conjugate vaccines. J Med Microbiol 2002;51:98-104.

25. Reinert RR. Pneumococcal conjugate vaccines - a European perspective. Int J Med Microbiol 2004;294:277-94.

26. Lagos R, Muñoz A, Valenzuela MT, Heitmann I, Levine MM. Population-based surveillance for hospitalized and ambulatory pediatric invasive pneumococcal disease in Santiago, Chile. Pediatr Infect Dis J 2002;21:1115-23.

27. Valenzuela MT, O'Loughlin R, De La Hoz F, Gomez E, Constenla D, Sinha A, et al. The burden of pneumococcal disease among Latin American and Caribbean children: Review of the evidence. Rev Panam Salud Publica 2009;25:270-9.

28. Cillóniz C, Ewig S, Polverino E, Marcos MA, Esquinas C, Gabarrús A, et al. Microbial aetiology of community-acquired pneumonia and its relation to severity. Thorax 2011;66:340-6.

29. Almirall J, Bolíbar I, Vidal J, Sauca G, Coll P, Niklasson B, et al. Epidemiology of community-acquired pneumonia in adults: $A$ population-based study. Eur Respir J 2000;15:757-63.

30. Mandell LA, Wunderink RG, Anzueto A, Bartlett JG, Campbell GD, Dean NC, et al. Infectious Diseases Society of America/American 
Thoracic Society consensus guidelines on the management of community-acquired pneumonia in adults. Clin Infect Dis 2007;44 Suppl 2:S27-72.

31. Jokinen C, Heiskanen L, Juvonen H, Kallinen S, Karkola K, Korppi $\mathrm{M}$, et al. Incidence of community-acquired pneumonia in the population of four municipalities in eastern Finland. Am J Epidemiol 1993; 137:977-88.

32. Cillóniz C, Polverino E, Ewig S, Aliberti S, Gabarrús A, Menéndez $\mathrm{R}$, et al. Impact of age and comorbidity on cause and outcome in community-acquired pneumonia. Chest 2013; 144:999-1007.

33. Torres A, Peetermans WE, Viegi G, Blasi F. Risk factors for community-acquired pneumonia in adults in Europe: A literature review. Thorax 2013;68:1057-65.

34. Pifarre R, Falguera M, Vicente-de-Vera C, Nogues A. Characteristics of community-acquired pneumonia in patients with chronic obstructive pulmonary disease. Respir Med 2007; 101:2139-44.

35. Müllerova H, Chigbo C, Hagan GW, Woodhead MA, Miravitlles M, Davis $\mathrm{KJ}$, et al. The natural history of community-acquired pneumonia in COPD patients: A population database analysis. Respir Med 2012;106:1124-33.

36. From the Centers for Disease Control and prevention. revised classification system for HIV infection and expanded surveillance case definition for AIDS among adolescents and adults. JAMA 1993;269:460.

37. Benito N, Moreno A, Miro JM, Torres A. Pulmonary infections in HIV-infected patients: An update in the $21^{\text {st }}$ century. Eur Respir $\mathrm{J}$ 2012;39:730-45.

38. Feikin DR, Feldman C, Schuchat A, Janoff EN. Global strategies to prevent bacterial pneumonia in adults with HIV disease. Lancet Infect Dis 2004;4:445-55.

39. Cilloniz C, Torres A, Polverino E, Gabarrus A, Amaro R, Moreno E, et al. Community-acquired lung respiratory infections in HIVinfected patients: Microbial aetiology and outcome. Eur Respir J 2014;43:1698-708.

40. Yoon YK, Yang KS, Sohn JW, Lee CK, Kim MJ. Impact of preceding respiratory viral infections on the clinical severity of patients with pneumococcal pneumonia. Influenza Other Respir Viruses 2014;8:549-56.

41. Song JY, Nahm MH, Cheong HJ, Kim WJ. Impact of preceding flu-like illness on the serotype distribution of pneumococcal pneumonia. PLoS One 2014;9:e93477.

42. Piatti G, Gazzola T, Allegra L. Bacterial adherence in smokers and non-smokers. Pharmacol Res 1997;36:481-4.

43. Decramer M, Janssens W, Miravitlles M. Chronic obstructive pulmonary disease. Lancet 2012;379:1341-51.

44. Greenberg D, Givon-Lavi N, Broides A, Blancovich I, Peled N, Dagan R. The contribution of smoking and exposure to tobacco smoke to Streptococcus pneumoniae and Haemophilus influenzae carriage in children and their mothers. Clin Infect Dis 2006;42:897-903.

45. Gordin FM, Roediger MP, Girard PM, Lundgren JD, Miro JM, Palfreeman A, et al. Pneumonia in HIV-infected persons: Increased risk with cigarette smoking and treatment interruption. Am J Respir Crit Care Med 2008;178:630-6.

46. Garcia-Vidal C, Ardanuy C, Tubau F, Viasus D, Dorca J, Liñares J, et al. Pneumococcal pneumonia presenting with septic shock: Host- and pathogen-related factors and outcomes. Thorax 2010;65:77-81.

47. Bello S, Menéndez R, Torres A, Reyes S, Zalacain R, Capelastegui $A$, et al. Tobacco smoking increases the risk for death from pneumococcal pneumonia. Chest 2014;146:1029-37.

48. Almirall J, Serra-Prat M, Bolíbar I, Palomera E, Roig J, Hospital I, et al. Passive smoking at home is a risk factor for communityacquired pneumonia in older adults: A population-based casecontrol study. BMJ Open 2014;4:e005133.

49. Joshi PC, Guidot DM. The alcoholic lung: Epidemiology, pathophysiology, and potential therapies. Am J Physiol Lung Cell Mol Physiol 2007;292:L813-23.
50. Bhatty M, Pruett SB, Swiatlo E, Nanduri B. Alcohol abuse and Streptococcus pneumoniae infections: Consideration of virulence factors and impaired immune responses. Alcohol 2011;45:523-39.

51. Samokhvalov AV, Irving HM, Rehm J. Alcohol consumption as a risk factor for pneumonia: A systematic review and meta-analysis. Epidemiol Infect 2010;138:1789-95.

52. de Roux A, Cavalcanti M, Marcos MA, Garcia E, Ewig S, Mensa J, et al. Impact of alcohol abuse in the etiology and severity of community-acquired pneumonia. Chest 2006;129:1219-25.

53. Fernández-Solá J, Junqué A, Estruch R, Monforte R, Torres A, Urbano-Márquez $\mathrm{A}$. High alcohol intake as a risk and prognostic factor for community-acquired pneumonia. Arch Intern Med 1995; 155: 1649-54.

54. Martí A, Marcos A, Martínez JA. Obesity and immune function relationships. Obes Rev 2001;2:131-40.

55. Huttunen R, Syrjänen J. Obesity and the outcome of infection. Lancet Infect Dis 2010;10:442-3.

56. Gladstone RA, Jefferies JM, Faust SN, Clarke SC. Continued control of pneumococcal disease in the UK - the impact of vaccination. $J$ Med Microbiol 2011;60:1-8.

57. Liu Z, Nachamkin I, Edelstein PH, Lautenbach E, Metlay JP. Serotype emergence and genotype distribution among macrolideresistant invasive Streptococcus pneumoniae isolates in the postconjugate vaccine (PCV-7) era. Antimicrob Agents Chemother 2012; $56: 743-50$.

58. Jansen AG, Rodenburg GD, van der Ende A, van Alphen L, Veenhoven $\mathrm{RH}$, Spanjaard $\mathrm{L}$, et al. Invasive pneumococcal disease among adults: Associations among serotypes, disease characteristics, and outcome. Clin Infect Dis 2009;49:e23-9.

59. Centers for Disease Control and Prevention (CDC), Advisory Committee on Immunization Practices. Updated recommendations for prevention of invasive pneumococcal disease among adults using the 23-valent pneumococcal polysaccharide vaccine (PPSV23). MMWR Morb Mortal Wkly Rep 2010;59:1102-6.

60. de Roux A, Schmidt N, Rose M, Zielen S, Pletz M, Lode H. Immunogenity of the pneumococcal polysaccharide vaccine in COPD patients. The effect of systemic steroids. Respir Med 2004; $98: 1187-94$.

61. Moberley S, Holden J, Tatham DP, Andrews RM. Vaccines for preventing pneumococcal infection in adults. Cochrane Database Syst Rev 2013;1:CD000422.

62. Paradiso PR. Advances in pneumococcal disease prevention: 13-valent pneumococcal conjugate vaccine for infants and children. Clin Infect Dis 2011;52:1241-7.

63. Rozenbaum $M H$, Sanders $E A$, van Hoek AJ, Jansen $A G$, van der Ende A, van den Dobbelsteen G, et al. Cost effectiveness of pneumococcal vaccination among Dutch infants: Economic analysis of the seven valent pneumococcal conjugated vaccine and forecast for the 10 valent and 13 valent vaccines. BMJ 2010;340:c2509.

64. Reinert R, Jacobs MR, Kaplan SL. Pneumococcal disease caused by serotype 19A: Review of the literature and implications for future vaccine development. Vaccine 2010;28:4249-59.

65. van Gils EJ, Veenhoven RH, Hak E, Rodenburg GD, Keijzers WC, Bogaert $\mathrm{D}$, et al. Pneumococcal conjugate vaccination and nasopharyngeal acquisition of pneumococcal serotype 19A strains. JAMA 2010;304:1099-106.

66. Choi EH, Kim SH, Eun BW, Kim SJ, Kim NH, Lee J, et al. Streptococcus pneumoniae serotype 19A in children, South Korea. Emerg Infect Dis 2008; 14:275-81.

67. American Academy of Pediatrics Committee on Infectious Diseases. Recommendations for the prevention of Streptococcus pneumoniae infections in infants and children: Use of 13-valent pneumococcal conjugate vaccine (PCV13) and pneumococcal polysaccharide vaccine (PPSV23). Pediatrics 2010;126:186-90.

68. Ben-Shimol S, Greenberg D, Givon-Lavi N, Schlesinger $Y$ Somekh E, Aviner S, et al. Early impact of sequential introduction of 7-valent and 13-valent pneumococcal conjugate vaccine on 
Cillóniz and Torres: Pneumococcal disease

IPD in Israeli children $<5$ years: An active prospective nationwide surveillance. Vaccine 2014;32:3452-9.

69. Skinner JM, Indrawati L, Cannon J, Blue J, Winters M, Macnair J, et al. Pre-clinical evaluation of a 15-valent pneumococcal conjugate vaccine (PCV15-CRM197) in an infant-rhesus monkey immunogenicity model. Vaccine 2011;29:8870-6.

70. Bologa M, Kamtchoua T, Hopfer R, Sheng X, Hicks B, Bixler G, et al. Safety and immunogenicity of pneumococcal protein vaccine candidates: Monovalent choline-binding protein A ( $P c p A)$ vaccine and bivalent PcpA-pneumococcal histidine triad protein $D$ vaccine. Vaccine 2012;30:7461-8.

71. Lynch JP $3^{\text {rd }}$, Zhanel GG. Streptococcus pneumoniae: Does antimicrobial resistance matter? Semin Respir Crit Care Med 2009;30:210-38.

How to cite this article: Cillóniz C, Torres A. Pneumococcal disease: Epidemiology and new vaccines. Community Acquir Infect 2014;1:35-43.

Source of Support: Nil, Conflict of Interest: None declared 